\title{
Mapping of quantitative trait loci for seminal vesicle mass and litter size to rat chromosome 8
}

\author{
V. Zídek ${ }^{1}$, J. Pintír ${ }^{1,2}$, A. Musilová ${ }^{1}$, V. Bíláa ${ }^{3}$, V. Křen ${ }^{1,3}$ and M. Pravenec ${ }^{1,3}$ \\ ${ }^{1}$ Institute of Physiology, Czech Academy of Sciences, Prague; ${ }^{2}$ Agronomical Faculty, Czech Agricultural University, Prague; \\ and ${ }^{3}$ Institute of Biology and Medical Genetics, $1^{\text {st }}$ Medical Faculty, Charles University, Prague, Czech Republic
}

\begin{abstract}
The spontaneously hypertensive rat (SHR) and the Brown Norway (BN) rat differ significantly in litter size (7.6 versus 4.5 pups). In the HXB and $\mathrm{BXH}$ sets of recombinant inbred (RI) strains derived from SHR and BN rats, heritability of litter size and of selected male reproductive parameters such as sperm production, sperm count, sperm morphology and motility, and the mass of the testis, epididymides, and seminal vesicles were estimated and a search was undertaken for quantitative trait loci (QTL) associated with these phenotypes. The mass of seminal vesicles was significantly associated with a QTL near the D8Cebr204S21 marker on chromosome 8 (LOD score $=4.1, P=0.00001$ ); this QTL was responsible for $46 \%$ of the genetic variability of the trait. The same gene marker on chromosome 8 also showed a suggestive association with the litter size. Litter size was significantly correlated with the mass of seminal vesicles $(r=0.58$, $P=0.003$ ). These findings indicate that the variability in litter size among RI strains may be due in part to differences in the mass of seminal vesicles and it is possible that both mass of seminal vesicles and litter size are determined by a pleiotropic effect of the same QTL on rat chromosome 8.
\end{abstract}

\section{Introduction}

Inbred strains of mice and rats differ significantly in their prolificacy, indicating that genetic factors have an important role in determining this phenotype. This hypothesis was tested by selection experiments in mice and the results showed that selection affects litter size and concomitantly growth and ovulation rate (Bradford, 1971; Durrant et al., 1980; Pomp et al., 1988; Bünger et al., 1992). In addition, correlated responses were also observed in some male reproductive traits (Land, 1973; Mafizul-Islam et al., 1976; Eisen and Johnson, 1981). The genetic factors that underlie litter size and the observed genetic correlations remain to be identified. One approach is to search for responsible genes by a total genome scan; for example, Kirkpatrick et al. (1998) described quantitative trait loci (QTL) for litter size and growth on several mouse chromosomes. In the present study, genetic and correlation analysis of litter size and selected male reproductive traits were performed using $\mathrm{HXB}$ and $\mathrm{BXH}$ recombinant inbred (RI) strains that were derived from the spontaneously hypertensive rat (SHR) and the Brown Norway (BN) rat, which differ significantly in litter size.

\section{Materials and Methods}

\section{Animals}

Progenitor strains SHR/Olalpcv (referred to as SHR) $(n=9)$ and BN-Lx/Cub (referred to as BN) $(n=9)$, and $24 \mathrm{RI}$ Revised manuscript received 3 February 1999. strains, $17 \mathrm{HXB} / \mathrm{Ipcr}$ and $7 \mathrm{BXH} / \mathrm{Cub}$ strains (at least five males per strain) (Pravenec et al., 1989) were used. The males from each strain were usually from two litters and no adjustment for litter size was conducted at birth. The SHR progenitor strain was originally obtained from the National Institute of Health and was maintained by brother $\times$ sister mating at the Czech Academy of Sciences for more than 15 years. The rats were at the $\mathrm{F}_{48}$ generation when the SHR colony was established in Prague. The BN-Lx progenitor is a BN congenic strain that carries a segment of chromosome 8 from the polydactylous (PD) strain (Křen et al., 1996). The RI strains were all beyond the $F_{38}$ generation. The results of DNA fingerprinting and PCR microsatellite tests confirmed that all strains were highly inbred (Pravenec et al., 1991a,b, 1996). The animals were housed and studied in the Institute of Physiology, Czech Academy of Sciences, Prague, in standard laboratory conditions: temperature $21^{\circ} \mathrm{C}$, humidity $55 \%$, light from $06: 00 \mathrm{~h}$ to $18: 00 \mathrm{~h}$. The rats were fed a standard pelleted laboratory chow ST-1 (VELAZ, Prague) and were given access to tap water ad libitum.

\section{Experimental procedures}

At 90 days of age, the male rats were killed with an overdose of thiopental (SPOFA, Prague) and the masses of their testes, epididymides, and seminal vesicles were determined. Sperm motility was estimated according to the methods of Working and Hurt (1987) and Seed et al. (1996). Immediately after excision, the left cauda epididymidis was cut with scissors and incubated for $2 \mathrm{~min}$ in $1 \mathrm{ml}$ flushing 
medium (Medi-Cult, Copenhagen). Motility was evaluated by observing at least 100 spermatozoa in ten different fields under light microscope and was expressed as percentage of motile spermatozoa. The number of spermatozoa was estimated according to the methods of Slot et al. (1993). The right cauda epididymidis was placed in $8 \mathrm{ml}$ Leibovitz medium (Serva Feinbiochemica, Heidelberg), cut several times with scissors and incubated for $90 \mathrm{~min}$ at $38-39^{\circ} \mathrm{C}$. After incubation, the total number of spermatozoa was counted using a Bürker haemocytometer. The number of spermatozoa was expressed as $1 \times 10^{7} \mathrm{ml}^{-1} \mathrm{~g}^{-1}$ tissue. Sperm production per day was estimated by dividing the number of spermatozoa by six, which corresponds to the duration of a seminiferous cycle ( 6 days) during which developing spermatozoa are in the spermatid stage (Aman et al., 1976). Sperm morphology was estimated according to the method of Michael et al. (1989). A drop of sperm suspension (the same sample that was used for the sperm count) was placed on a glass slide and allowed to dry and the spermatozoa were stained with Welsch I solution. A total of 200 spermatozoa was examined for morphology under a light microscope (at $\times 1000$ magnification). Results were expressed as percentage of normal spermatozoa. Litter size (live born) was evaluated by counting at least 20 litters per progenitor and RI strain; the females were always mated at 10 weeks of age and only first parity litters were evaluated. The duration for the estimation of litter size in all strains was approximately 2 years.

\section{Statistical analysis}

Values are expressed as means \pm SD. Heritabilities of the traits were estimated according to the method of Plomin and McClearn (1993) from the variance in mean values between and within the RI strains. The additive genetic variance was estimated as $50 \%$ of the total variance between the means of the RI strains; the environmental variance was estimated to be the average variance in mean phenotypical values within the RI strains. Narrow heritability was calculated by dividing the additive genetic variance by the sum of the additive genetic variance and the environmental variance.

The number of effective factors in RI strains was estimated according to the equation $L=D^{2} / 2 V$, where $D$ is the difference between the highest and the lowest mean and $V$ is the variance of the means of all RI and progenitor strains of the set (Bailey, 1981). The method for estimation of the number of genes was introduced by Wright (1952) and by Mather and Jinks (1971) and the application for RI strains was made by Taylor (1976). This method is based on four assumptions: (i) of all possible genotypes, the two that express the highest and lowest mean values are included in calculations of estimated variance; (ii) the loci have equal effects on the trait; (iii) the loci are unlinked; (iv) there is no epistacy. Since most of these assumptions are not likely to be satisfied, the number of estimated genes is lower than the reality and therefore it was suggested that the term 'number of effective factors' was used rather than 'number of genes'.

Map Manager QT program (version b18) (Manly, 1997) was used to test for single locus associations by regression analysis and the significance of each potential association was measured using the likelihood ratio statistics (LRS) of Haley and Knott (1992). The interval regression method of Map Manager QT was used to test for QTL within marker intervals. The significance threshold for the genome-wide scan was determined empirically by the Map Manager QT permutation test using the informative markers and 1000 permuted data sets as recommended by Doerge and Churchill (1996). The likelihood ratio scores of 6.0 and 16.3 were used for detection of suggestive and significant associations between gene markers and the respective phenotypes. Significant linkage was defined in accordance with the guidelines of Lander and Kruglyak (1995) as statistical evidence occurring by chance in the genome scan with a probability of $5 \%$ or less. One-half of the fraction of variance attributable to a QTL in the RI strains was used to estimate the QTL effect expected in a comparable $F_{2}$ population derived from the progenitors (to correct for the doubling effect of inbreeding on additive genetic variance) (Belknap et al., 1996). The fraction of genetic variance contributed by the QTL was determined by dividing the estimated QTL effect by the heritability.

\section{Gene map of RI strains}

Strain distribution patterns of more than 700 markers in the HXB and BXH RI strains were available for the QTL analysis (Pravenec et al., 1996). Over 150 new artificial fragment length polymorphism (AFLP) markers were identified in RI strains (L. F. M. van Zutphen, H. Van Lith and M. Den Bieman, unpublished). The D8Cebr204S21 marker, originally D10Cebr204S21 (Pravenec et al., 1996), was found to be closely linked to chromosome 8 markers (LOD score 5.6) and was therefore assigned to chromosome 8 (M. Pravenec and V. Křen, unpublished).

\section{Results}

There were no significant differences in male reproductive parameters between the two progenitor strains, but litter size was significantly higher in the SHR strain (Table 1). The distribution of male reproductive traits was continuous and showed significant variability among RI strains (Fig. 1) which implies several genes are involved in determining each trait. The minimum number of effective factors responsible for the observed variation and the narrow heritability of all traits is shown (Table 2). The estimates of the minimum number of effective factors for all eight traits are low and very similar and vary between 7.4 and 9.9 .

An almost complete genome scan of the HXB and BXH RI strains with more than 700 markers was performed using the Map Manager QT program to search for QTL associated with these reproductive parameters. The mass of seminal vesicles was significantly associated with a QTL near the D8Cebr204S21 marker on chromosome 8 (LOD score $=4.1$, $P=0.00001$ ) (Table 3 ). The simple interval mapping of seminal vesicle mass with the chromosome 8 markers depicting the likelihood ratio statistics are shown (Fig. 2). This putative QTL was responsible for $46 \%$ of the genetic 
Table 1. Male reproductive traits and litter size in rat progenitor strains

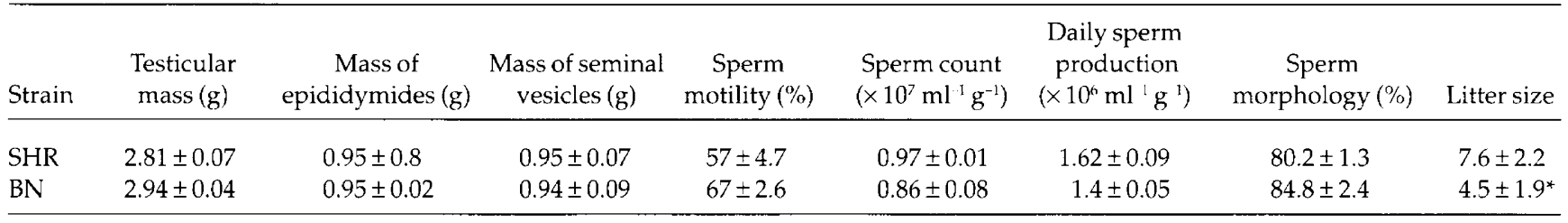

Asterisk denotes statistical significance, $P=0.005$.
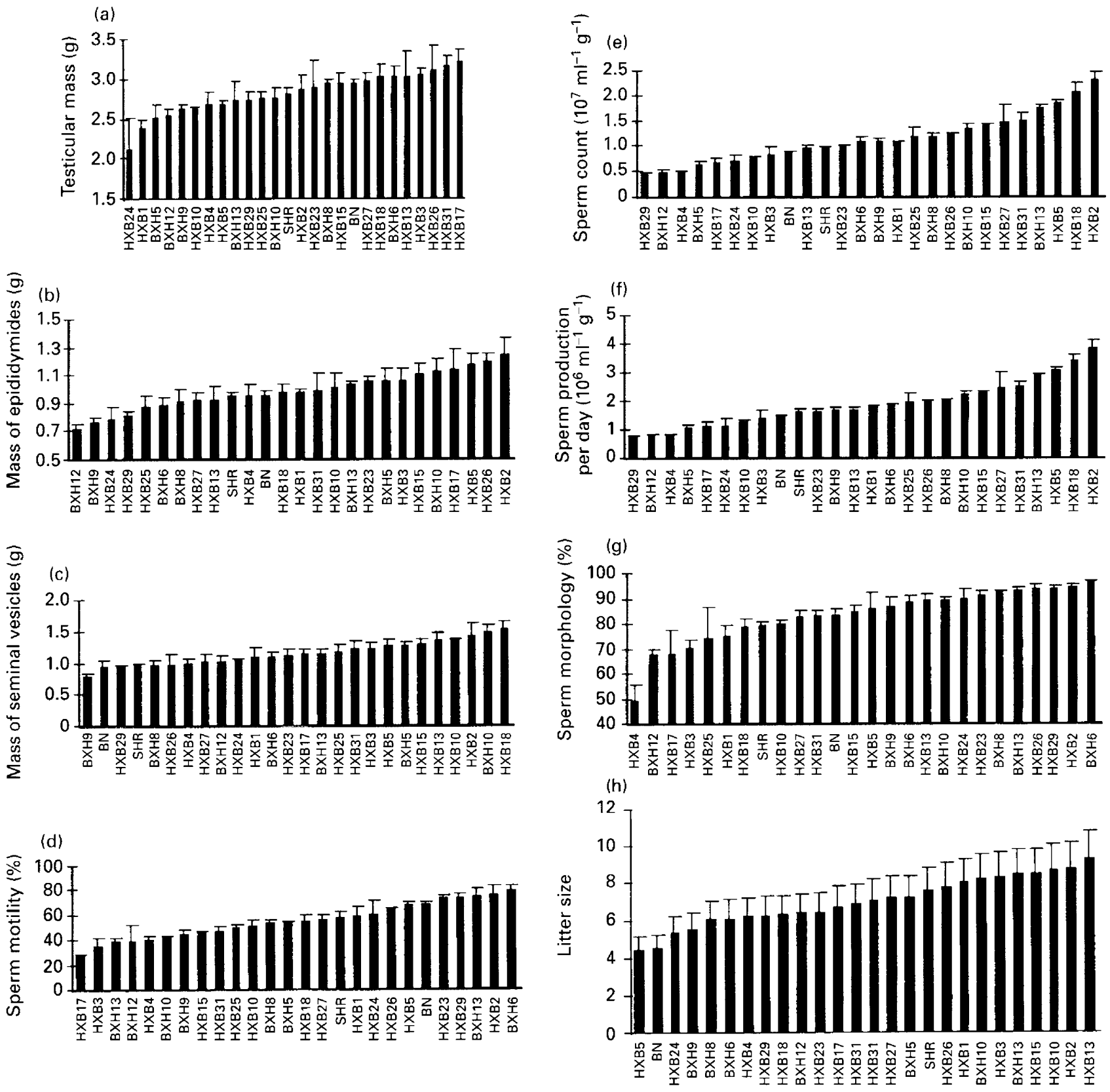

Fig. 1. Distribution of mean \pm SD of selected male reproductive parameters and litter size among rat RI strains and progenitor strains: (a) testicular mass, (b) mass of epididymides; (c) mass of seminal vesicles; (d) sperm motility; (e) sperm count; (f) sperm production per day; (g) sperm morphology; and (h) litter size. 
Table 3. Association of rat reproductive parameters with gene markers as estimated by the simple interval mapping

\begin{tabular}{llccc}
\hline Reproductive trait & \multicolumn{1}{c}{ Marker } & Chromosome & $\begin{array}{c}\text { Likelihood ratio } \\
\text { statistics }\end{array}$ & LOD score \\
\hline Mass of epididymides & D10Cebrp1016s5 & 10 & 11.1 & 2.41 \\
Mass of seminal vesicles & D8Cebr204s21 & 8 & $19.0^{*}$ & $4.10^{+}$ \\
Sperm motility & Prph & 7 & 9.7 & 2.11 \\
Sperm count & D2Cebr104s1 & 2 & 10.6 & 2.30 \\
Sperm production per day & D2Cebr104s1 & 2 & 10.5 & 2.28 \\
Sperm morphology & D8Ucsf2 & 8 & 10.3 & 2.24 \\
Litter size & D8Cebr204S21 & 8 & 11.6 & 2.54 \\
\hline
\end{tabular}

The likelihood ratio scores of 6.0 and 16.3, as calculated by the permutation test of the Map Manager QT program, were used for detection of suggestive and significant associations between gene markers and the respective phenotype. Asterisk denotes statistically significant result.

Table 2. Minimum number of effective factors responsible for variation and narrow heritability of reproductive traits in rats

\begin{tabular}{lcc}
\hline Reproductive trait & $\begin{array}{c}\text { Minimum number } \\
\text { of effective factors }\end{array}$ & $\begin{array}{c}\text { Narrow } \\
\text { heritability }\end{array}$ \\
\hline Testicular mass & 9.8 & 0.49 \\
Mass of epididymides & 7.9 & 0.58 \\
Mass of seminal vesicles & 8.2 & 0.57 \\
Sperm motility & 7.5 & 0.78 \\
Sperm count & 7.5 & 0.89 \\
Sperm production per day & 7.6 & 0.89 \\
Sperm morphology & 9.9 & 0.76 \\
Litter size & 7.4 & 0.20 \\
\hline
\end{tabular}

variability of the trait (one-half of the fraction of variance attributable to a QTL in the RI strains was $0.53 / 2=0.265$; the fraction of genetic variance contributed by the QTL was determined by dividing the estimated QTL effect by the heritability: $0.265 / 0.57=0.46$ ).

Since previous data from selection experiments showed significant genetic correlations between growth, litter size and male reproductive traits, the relationship between litter size and male reproductive parameters in RI strains was investigated and a significant correlation between litter size and the mass of seminal vesicles was found $(r=0.58$, $P=0.003)$.

\section{Discussion}

The results of the present study showed that litter size was significantly correlated with mass of seminal vesicles. The fluid secreted from the seminal vesicles forms the main part of the seminal plasma in rats, and it has a number of effects that ensure fertility (Curry and Atherton, 1990). In rats, the secretions of the seminal vesicles and coagulating glands clot after ejaculation in the female tract to form a copulatory plug. The plug plays a critical role in transcervical sperm transport, as demonstrated by the effects of surgical removal of seminal vesicles and coagulating glands on mating and fertility (Cukierski et al., 1991). After removal of seminal

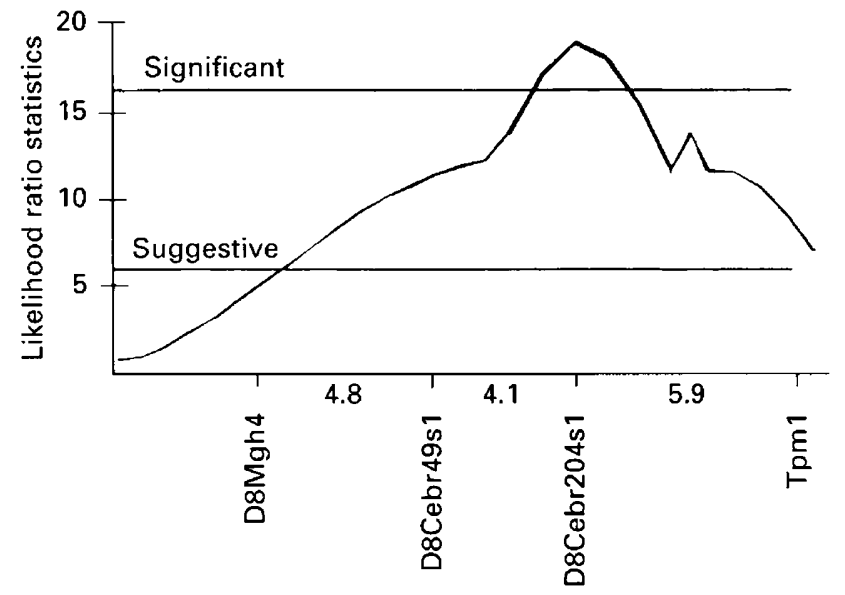

Fig. 2. Interval mapping of the quantitative trait loci associated with the mass of seminal vesicles. Likelihood ratio statistics from the Map Manager QT linkage analysis are plotted across the segment of rat chromosome 8. Estimated distances between markers are in centimorgans (cM) (Pravenec et al., 1996). The horizontal lines indicate the thresholds for statistical significance of the likelihood ratio statistics determined by the Map Manager QT permutation test. The LOD scores are obtained by dividing the likelihood ratio statistics by 4.6 .

vesicles, males were completely infertile because they could not produce a copulatory plug (Cukierski et al., 1991). Carballada and Esponda (1992) studied the relationship between the quantity of seminal vesicle secretion in the ejaculate and the percentage of spermatozoa reaching the uterus. When the seminal vesicles were partially removed, the plug was not properly formed and the number of fetuses showed a close correlation with the quantity of seminal secretion.

An almost complete genome scan resulted in identification of a QTL on chromosome 8 that was significantly associated with seminal vesicle mass and suggestively associated with litter size. Genetic studies in mice (Pomp et al., 1995; Spearow et al., 1995) indicated that QTL for litter size, ovulation rate, embryo survival and hormone-induced ovulation rate are present on mouse chromosomes 2, 4, 9 and 11. In addition, Kirkpatrick et al. (1998) reported QTL for litter size on mouse 
chromosomes 2, 4, 9, 11 and 13. Mouse chromosome 9, on which QTL for litter size, ovulation rate and embryo survival were mapped (Spearow et al., 1995; Kirkpatrick et al., 1998), is largely homologous to rat chromosome 8, on which a QTL associated with seminal vesicles mass (significant association with the D8Cebr204S21 marker) and with litter size (suggestive association with the same marker) was identified in the present study. Identification of a QTL that is responsible for seminal vesicle mass and litter size is an important first step in the process of identifying genes that play significant roles in the control of reproductive traits in rats. Further studies, including the production of congenic strains, are necessary to map this putative QTL more precisely.

This work was supported by grant 301/96/0897 from the Grant Agency of the Czech Republic and a grant 96005 from the US-CZ Science and Technology Program. The research of M. Pravenec was supported in part by an International Research Scholar's Award from the Howard Hughes Medical Institute.

\section{References}

Aman RP, Johnson L, Thompson DL and Picket BW (1976) Daily spermatozoal production, epididymal spermatozoal reserves and transit time of spermatozoa through the epididymis of the rhesus monkey Biology of Reproduction 15 586-592

Bailey DW (1981) Recombinant and bilineal congenic strains. In The Mouse in Biological Research. 1. History, Genetics and Wild Mice pp 223-229 Eds HL Foster, JD Small and JD Fox. Academic Press, New York

Belknap JK, Mitchell SR, O'Toole LA, Helms ML and Crabbe JC (1996) Type I and type II error rates for quantitative trait loci (QTL) mapping studies using recombinant inbred mouse strains Behavior Genetics 26 149-160

Bradford GE (1971) Growth and reproduction in mice selected for rapid body weight gain Genetics 69 499-512

Bünger L, Renne U and Diett G (1992) Selection for body weight at 42 days in laboratory mice with and without litter size standardization - direct response and correlated effects on litter size Archioes of Animal Breeding 35 305-319

Carballada R and Esponda P (1992) Role of fluid from seminal vesicles and coagulating glands in sperm transport into the uterus and fertility Joumal of Reproduction and Fertility 95 639-648

Cukierski MA, Sina JL, Prahalada S and Robertson RT (1991) Effects of seminal vesicle coagulating gland ablation on fertility in rats Reproductive Toxicology 5 347-352

Curry PT and Atherton RW (1990) Seminal vesicles: development, secretory products, and fertility Archives of Andrology 25 107-113

Doerge RW and Churchill GA (1996) Permutation tests for multiple loci affecting a quantitative character Genetics 142 285-294

Durrant BS, Eisen EJ and Ulberg LC (1980) Ovulation rate, embryo survival and ovarian sensitivity to gonadotrophins in mice selected for litter size and body weight Journal of Reproduction and Fertility 59329-339

Eisen EJ and Johnson BH (1981) Correlated responses in male reproductive traits in mice selected for litter size and body weight Genetics 99 513-524
Haley CS and Knott SA (1992) A simple regression method for mapping quantitative trait loci in line crosses using flanking markers Heredity 69 315-324

Kirkpatrick BW, Mengelt A, Schulman N and Martin ICA (1998) Identification of quantitative trait loci for prolificacy and growth in mice Mammalian Genome 9 97-102

Křen V, Bílá V, Kašpárek R, Křenová D, Pravenec M and Rapp K (1996) Recombinant inbred and congenic strains of the rat for genetic analysis of limb morphogenesis Folia Biologica (Praha) 42 163-170

Land RB (1973) The expression of female sex-limited characters in the male Nature $241208-209$

Lander E and Kruglyak L (1995) Genetic dissection of complex traits: guidelines for interpreting and reporting linkage results Nature Genetics 11 241-247

Mafizul-Islam ABM, Hill WG and Land RB (1976) Ovulation rate of lines of mice selected for testis weight Genetic Research 27 23-32

Manly K (1997) Map Manager QT http://mcbio.med.buffalo.edu/ mmQT.html

Mather K and Jinks JL (1971) Biometrical Genetics 2nd Edn Cornell University Press, Ithaca, New York

Michael R, Downing JC and Edgcomb JC (1989) Effect of metronidazole on fertility and testicular function in male rats Fundamental Toxicology 12 386-396

Plomin R and McClearn GE (1993) Quantitative trait loci (QTL) analyses and alcohol-related behaviors Behavior Genetics 23 197-211

Pomp D, Eisen EJ and Ziecik AJ (1988) LH receptor induction and ovulation rate in mice selected for litter size and body weight Journal of Reproduction and Fertility $84601-609$

Pomp D, Foster S, Cushman MA and Eisen G (1995) Identification of genes controlling quantitative reproduction traits in mice Biology of Reproduction 52 Supplement 161

Pravenec M, Klír P, Křen V, Zicha J and Kuneš J (1989) An analysis of spontaneous hypertension in spontaneously hypertensive rats by means of new recombinant inbred strains Journal of Hypertension 7 217-222

Pravenec M, Křen V, Kuně J, Scicli AG, Carretero AO, Simonet L and Kurtz TW (1991a) Cosegregation of blood pressure with an RFLP in the kallikrein gene family Hypertension 17 242-246

Pravenec M, Simonet L, Kł̌en V, Kuneš J, Levan G, Szpirer J, Szpirer C and Kurtz TW (1991b) The rat renin gene: assignment to chromosome 13 and linkage to the regulation of blood pressure Genomics $9466-472$

Pravenec M, Gauguier D, Schott J-J et al. (1996) A genetic linkage map of the rat derived from recombinant inbred strains Mammalian Genome 7 117-127

Seed JG, Waller P, Brian H, Vickery JD and Zaneveld H (1996) The effect of ketonazole on fertility of male rats Journal of Pharmacology and Experimental Therapy 6 123-124

Slot H, Flores C, Carboni A and Menon M (1993) Cyclosporine: its effect on testicular function and fertility in the prepubertal rat Journal of Andrology 11 $17-24$

Spearow JL, Keisner S, Carr L, Peters M, Barthelow J, Faridi J and Barkley M (1995) Identification of genes controlling quantitative reproduction traits in mice Biology of Reproduction 52 Supplement 161

Taylor BA (1976) Genetic analysis of susceptibility to isoniazid-induced seizures in mice Genetics $83373-377$

Working PJ and Hurt G (1987) Assessment of the role of Leydig cell products other than testosterone in spermatogenesis and fertility in adult rats International Journal of Andrology 11 507-523

Wright S (1952) The genetics of quantitative variability. In Quantitative Inheritance pp 5-41 Eds ECR Reeve and C Waddington. HM Stationery Office, London 